\title{
EFEKTIFITAS AIR KELAPA HIJAU MUDA TERHADAP PENURUNAN TEKANAN DARAH TINGGI PADA LANSIA DI POSYANDU USILA PUSKESMAS PERAK TIMUR SURABAYA
}

\author{
Ninik Ambar Sari , Dya Sustrami \\ Program Studi DIII Keperawatan \\ Stikes Hang Tuah Surabaya \\ Email : niniksht@gmail.com
}

\begin{abstract}
Hypertension is an increase in blood pressure where the systolic pressure is more than $140 \mathrm{mmHg}$ and diastolic pressure is more than $90 \mathrm{mmHg}$. The cause of the onset of hypertension can be of age factor. Elderly who suffer from hypertension usually cause interruption of daily activities, so routine treatment is needed in order not to cause complications. Young coconut water contains potassium, magnesium and vitamin $C$ which has benefits to help the body regulate blood pressure, so it can reduce hypertension. The purpose of this study was to determine the effect of young coconut water on the decrease of high blood pressure in the elderly. Experimental Quasy research design with Non-Equivalent Control Group Desaign approach. The population of this study is elderly who are not dependence of hypertension drugs as much as 32 people with the number of samples of 30 respondents selected by Probability Sampling with Simple Random Sampling approach. The independent variable is young coconut water therapy, the dependent variable is the decrease of high blood pressure. Data were collected using questionnaires and observations. Data were analyzed by using Paired t-test and Independent $t$-test. The results showed that the consumption of young coconut water as much as $250 \mathrm{ml}$ morning and afternoon for 2 weeks in the treatment group can lower systolic blood pressure. The independent $t$ test in the treatment group and the control group obtained the result $p$ $=0.013(p<a=0.05)$. The implication of this study is that young coconut water can lower blood pressure in elderly people with hypertension, so that young coconut water treatment can be used as one of the non-pharmacological alternative to reduce blood pressure.
\end{abstract}

\section{Keywords: Young coconut water, hypertension, elderly}

Abstrak: Hipertensi merupakan kenaikan tekanan darah dimana tekanan sistolik lebih dari $140 \mathrm{mmHg}$ dan tekanan diastolik lebih dari $90 \mathrm{mmHg}$. Penyebab dari timbulnya hipertensi bisa dari faktor umur. Lansia yang menderita hipertensi biasanya menyebabkan tergganggunya aktifitas sehari-hari, sehingga diperlukan pengobatan secara rutin agar tidak menimbulkan komplikasi. Air kelapa muda mengandung kalium, magnesium dan vitamin $\mathrm{C}$ yang memiliki manfaat untuk membantu tubuh mengatur tekanan darah, sehingga dapat menurunkan hipertensi. Tujuan penelitian ini adalah untuk mengetahui pengaruh air kelapa muda terhadap penurunan tekanan darah tinggi pada lansia. Desain penelitian Quasy Eksperimental 
dengan pendekatan Non Equivalent Control Group Desaign. Populasi penelitian ini adalah lansia yang tidak ketergantungan obat hipertensi sebanyak 32 orang dengan jumlah sampel sebanyak 30 responden yang dipilih secara Probability Sampling dengan pendekatan Simple Random Sampling. Variabel independen adalah terapi air kelapa muda, variabel dependen adalah penurunan tekanan darah tinggi. Data dikumpulkan menggunakan kuesioner dan observasi. Data dianalisis dengan menggunakan uji Paired t-test dan Independent t-test. Hasil penelitian menunjukkan bahwa konsumsi air kelapa muda sebanyak $250 \mathrm{ml}$ pagi dan sore selama 2 minggu pada kelompok perlakuan dapat menurunkan tekanan darah sistolik. Uji independent $t$ test pada kelompok perlakuan dan kelompok kontrol didapatkan hasil $p=0.013$ ( $p<$ $a=0.05$ ). Implikasi penelitian ini adalah air kelapa muda dapat menurunkan tekanan darah pada lansia yang menderita hipertensi, sehingga terapi air kelapa muda dapat dijadikan sebagai salah satu pengobatan alternatif non-farmakologi untuk menurunkan tekanan darah.

\section{Kata kunci : Air kelapa muda, hipertensi, lansia}

\section{PENDAHULUAN}

Hipertensi adalah suatu keadaan seseorang mengalami peningkatan tekanan darah di atas normal yang mengakibatkan peningkatan angka kesakitan (morbiditas) dan angka kematian (mortalitas) (Reny, 2016). Lansia adalah seseorang yang mencapai usia lebih dari 60 tahun. Secara umum pada lansia, hipertensi didefinisikan sebagai tekanan sistolik $\geq 140 \mathrm{mmHg}$ dan tekanan diastolik $\geq$ $90 \mathrm{mmHg}$ (Laode, 2012). Hipertensi menjadi masalah karena paling banyak ditemui pada lansia. Lebih dari separuh kematian diatas usia 60 tahun, disebabkan oleh penyakit jantung dan serebrovaskular (Nugroho, 2008). Hipertensi tersebut juga dapat mengganggu aktifitas sehari-hari, maka dari itu sangat diperlukan untuk menjalani pengobatan secara rutin agar tidak menimbulkan komplikasi.

Hipertensi dapat dikendalikan dengan pengobatan farmakologi dan non-farmakologi. Pengobatan farmakologi merupakan pengobatan menggunakan anti hipertensi untuk menurunkan tekanan darah (Ardiansyah, 2012). Pengobatan anti hipertensi antara lain dengan diuretik, antagonis kalsium, dan vasodilator (Reny, 2016). Pengobatan Farmakologi dinilai sebagai pengobatan jangka panjang yang membutuhkan biaya cukup besar dan menimbulkan efek samping bagi tubuh, disamping itu masyarakat sering tidak mematuhi untuk minum obat anti hipertensi secara teratur, sehingga masyarakat memilih menggunakan obat non-farmakologi merupakan pengobatan tanpa obatobatan (Fahriza., et al, 2014). Salah satu bentuk pengobatan herbal dengan minum air kelapa muda (Vita, 2016).

Berdasarkan hasil studi pendahuluan peneliti di Posyandu Usila Puskesmas Perak Timur Surabaya pada tanggal 20 Januari 2017, lansia yang menderita hipertensi belum memanfaatkan air kelapa muda sebagai alternatif untuk menurunkan tekanan darah karena mereka belum 
tahu manfaatnya. Selama ini mereka hanya mengkonsumsi obat-obatan anti hipertensi yang diberikan dari Puskesmas saja.

Prevalensi hipertensi di dunia tahun 2007, usia $>60$ tahun sebesar $60 \%$ dan pada usia dewasa sebesar 20$30 \%$ (Lam, et al, 2007). Prevalensi hipertensi di Indonesia, kelompok usia 55-64 tahun sebesar 45,9\%, pada kelompok usia 65-74 tahun sebesar $57,6 \%$ dan pada kelompok usia $>75$ tahun sebesar $63,8 \%$. Resiko hipertensi meningkat bermakna sejalan dengan bertambahnya usia mempunyai beresiko tinggi terserang hipertensi (Riskesdas, 2013). Hipertensi termasuk dalam kategori penyakit 10 terbanyak di kota Surabaya total penderita hipertensi pada tahun 2013 sebanyak 131.943 pasien (Dinkes Surabaya, 2015). Data awal yang diperoleh dari Posyandu Usila di Puskesmas Perak Timur Surabaya pada tanggal 20 Januari 2017, didapatkan data lansia yang ada ditempat itu ditemukan 32 orang lansia yang tidak ketergantungan obat hipertensi.

Banyak faktor yang dapat menyebabkan hipertensi, antara lain : faktor genetik, jenis kelamin, usia, konsumsi diet tinggi garam, obesitas, merokok, konsumsi alkohol, dan stres (Ardiansyah, 2012). Pada lansia mengalami penurunan elastisitas jaringan di pembuluh darah dan resiko terjadi arterosklerosis yang menyebabkan penurunan untuk memompa darah ke seluruh tubuh (Reny, 2016). Kemampuan jantung untuk memompa darah menurun $1 \%$ setiap tahun sesudah umur 20 tahun, hal ini akan berpengaruh pada lansia (Nugroho, 2008). Peningkatan tekanan darah secara terus menerus pada pasien hipertensi akan mengakibatkan kerusakan pembuluh darah pada organ-organ vital. Hal ini dapat menyebabkan infark miokard, stroke, ensefalopati pada otak dan gagal ginjal (Ardiansyah, 2012).

Pengobatan non-farmakologi yaitu dengan air kelapa muda. Karena air kelapa mempunyai kandungan yang terdiri dari $17 \%$ kalium, $15 \%$ magnesium dan $10 \%$ vitamin $\mathrm{C}$. Kandungan yang dimiliki air kelapa muda dipercaya dapat menurunkan tekanan darah (Darmawan, 2013). Air kelapa muda dapat digunakan dalam penanganan penyakit untuk menurunkan hipertensi (Vita, 2016). Mekanisme kerja kalium dalam menurunkan tekanan darah terjadi melalui natriuresis, penurunan renin angiotensin aldosteron (RAA) (Farapti $\&$ Sayogo, 2014).

Sebuah penelitian yang dilakukan oleh oleh Fahriza, et al (2014) tentang pengaruh terapi herbal air kelapa muda terhadap penurunan tekanan darah pada penderita hipertensi di Desa Tambahrejo Kecamatan Bandar Kabupaten Batang. Penelitian ini dilakukan selama 14 hari dengan memberikan air kelapa muda $250 \mathrm{ml}$ pagi dan sore. Hasil dari penelitian ini adalah ada pengaruh pemberian air kelapa muda terhadap penurunan tekanan darah sistolik dan diastolik pada penderita hipertensi.

Air kelapa muda merupakan minuman khas daerah tropis yang tinggi kalium. Air kelapa muda mengandung kalium $7300 \mathrm{mg} / \mathrm{L}$ dan natrium $1830 \mathrm{mg} / \mathrm{L}$. Seperti halnya air kelapa muda yang dikenal khasiatnya untuk menurunkan tekanan darah atau sebagai anti hipertensi. Kandungan 
mineral kalium yang dapat menjaga dinding pembuluh darah tetap elastis, mengurangi penyempitan pembuluh darah sehingga pembuluh darah menjadi lebar, mengurangi sekresi renin, menurunnya aldosteron dan mempunyai efek dalam pompa $\mathrm{Na}-\mathrm{K}$ yaitu kalium dipompa dari cairan ekstraseluler ke dalam sel, dan natrium di pompa keluar. Sehingga kalium dapat menurunkan tekanan darah (Muttaqin, 2009).

\section{METODE PENELITIAN}

Penelitian ini menggunakan desain penelitian quasy eksperimental dengan pendekatan non equivalent control group desaign. Populasi penelitian ini adalah responden yang tidak ketergantungan obat hipertensi sebanyak 32 orang. Sampel penelitian ini adalah seluruh responden yang menderita hipertensi sebanyak 30 responden yang dipilih secara probability sampling dengan pendekatan simple random sampling. Variabel independen adalah pengaruh air kelapa muda. Variabel dependen adalah penurunan tekanan darah tinggi.

Pengumpulan data terbagi atas data primer dan data sekunder. Data primer diperoleh dengan mendapatkan data/informasi langsung dari responden yang menjadi sasaran penelitian melalui wawancara kuesioner dan observasi pengukuran. Data sekunder diperoleh melalui telaah kepustakaan dan data yang diperoleh dari Posyandu Usila Puskesmas Perak Timur Surabaya. Instrumen penelitian menggunakan lembar observasi, tensimeter dan stetoskop. Data yang telah dikumpulkan selama penelitian dianalisis secara statistik dengan menggunakan uji Paired t-test dan Independent t-test.

\section{HASIL PENELITIAN}

\section{Karakteristik Responden Berdasarkan Jenis Kelamin}

Tabel 1. Karakteristik responden berdasarkan jenis kelamin

\begin{tabular}{ccccc}
\hline \multicolumn{3}{c}{ Kelompok Perlakuan } & \multicolumn{2}{c}{ Kelompok Kontrol } \\
\hline Jenis kelamin & Frekuensi $(f)$ & Prosentase (\%) & Frekuensi $(f)$ & Prosentase (\%) \\
\hline Laki-laki & 5 & 33.3 & 6 & 40 \\
Perempuan & 10 & 66.7 & 9 & 60 \\
\hline Total & 15 & 100 & 15 & 100 \\
\hline
\end{tabular}

\section{Karakteristik Responden Berdasarkan Usia}

Tabel 2. Karakteristik responden berdasarkan usia

\begin{tabular}{ccccc}
\hline \multicolumn{3}{c}{ Kelompok Perlakuan } & \multicolumn{2}{c}{ Kelompok Kontrol } \\
\hline $\begin{array}{c}\text { Usia } \\
\text { Responden }\end{array}$ & Frekuensi $(f)$ & Prosentase (\%) & Frekuensi (f) & Prosentase (\%) \\
\hline 60-74 tahun & 8 & 53.3 & 12 & 80
\end{tabular}




\begin{tabular}{ccccc}
$75-90$ tahun & 7 & 46.7 & 3 & 20 \\
\hline Total & 15 & 100 & 15 & 100 \\
\hline
\end{tabular}

3. Karakteristik Responden Berdasarkan Penghasilan Per Bulan

Tabel 3. Karakteristik responden berdasarkan penghasilan per bulan

\begin{tabular}{ccccc}
\hline \multicolumn{3}{c}{ Kelompok Perlakuan } & \multicolumn{2}{c}{ Kelompok Kontrol } \\
\hline $\begin{array}{c}\text { Penghasilan per } \\
\text { bulan }\end{array}$ & $\begin{array}{c}\text { Frekuensi } \\
(f)\end{array}$ & $\begin{array}{c}\text { Prosentase } \\
(\%)\end{array}$ & Frekuensi $(f)$ & $\begin{array}{c}\text { Prosentase } \\
(\%)\end{array}$ \\
\hline $\begin{array}{c}<1.000 .000 \\
1.000 .000-\end{array}$ & 9 & 60 & 14 & 93.3 \\
3.000 .000 & 6 & 40 & 1 & 6.7 \\
\hline Total & 15 & 100 & 15 & 100 \\
\hline
\end{tabular}

4. Karakteristik Responden Berdasarkan Riwayat Penyakit Dahulu

Tabel 4. Karakteristik responden berdasarkan riwayat penyakit dahulu

\begin{tabular}{ccccc}
\hline \multicolumn{2}{c}{ Kelompok Perlakuan } & \multicolumn{2}{c}{ Kelompok Kontrol } \\
\hline $\begin{array}{c}\text { Riwayat Penyakit } \\
\text { Frekuensi }\end{array}$ & $\begin{array}{c}\text { Prosentase } \\
(\%)\end{array}$ & $\begin{array}{c}\text { Frekuensi } \\
(f)\end{array}$ & $\begin{array}{c}\text { Prosentase } \\
(\%)\end{array}$ \\
\hline Asam Urat & 3 & 20 & 3 & 20 \\
Kolesterol & 1 & 6.7 & 3 & 20 \\
Tidak ada & 11 & 73.3 & 9 & 60 \\
\hline Total & 15 & 100 & 15 & 100 \\
\hline
\end{tabular}

5. Tekanan Darah Pretest dan Posttest Pada Kelompok Perlakuan

Tabel 5. Hasil statistik uji paired $t$ test pada kelompok perlakuan tekanan darah pre dan post

\begin{tabular}{ccccc}
\hline Tekanan Darah & \multicolumn{2}{c}{ Pretest } & \multicolumn{2}{c}{ Posttest } \\
\cline { 2 - 5 } Sistolik & $\mathrm{N}$ & $\%$ & $\mathrm{~N}$ & $\%$ \\
\hline Tetap & 0 & 0 & 3 & 20 \\
Turun & 0 & 0 & 10 & 66,7 \\
Naik & 15 & 100 & 2 & 13,3 \\
\hline Total & 15 & 100 & 15 & 100 \\
\hline & Uji paired t test $p=0.009$ & & \\
\hline
\end{tabular}

\section{Tekanan Darah Pretest dan Posttest Pada Kelompok Kontrol}

Tabel 6. Hasil statistik uji paired t test pada kelompok kontrol tekanan darah pre dan post

\begin{tabular}{ccccc}
\hline Tekanan Darah & \multicolumn{2}{c}{ Pretest } & \multicolumn{2}{c}{ Posttest } \\
\cline { 2 - 5 } Sistolik & $\mathrm{N}$ & $\%$ & $\mathrm{~N}$ & $\%$ \\
\hline Tetap & 0 & 0 & 9 & 60
\end{tabular}




\begin{tabular}{ccccc} 
Turun & 0 & 0 & 3 & 20 \\
Naik & 15 & 100 & 3 & 20 \\
\hline Total & 15 & 100 & 15 & 100 \\
\hline \multicolumn{6}{c}{ Uji paired t test $p=1.000$} \\
\hline
\end{tabular}

7. Tekanan Darah Posttest Pada Kelompok Perlakuan dan Kelompok Kontrol Tabel 7. Hasil statistik uji independent t test

\begin{tabular}{ccccc}
\hline Tekanan Darah & \multicolumn{2}{c}{ Perlakuan Posttest } & \multicolumn{2}{c}{ Kontrol Posttest } \\
\cline { 2 - 5 } Sistolik & $\mathrm{N}$ & $\%$ & $\mathrm{~N}$ & $\%$ \\
\hline Tetap & 3 & 20 & 9 & 60 \\
Turun & 10 & 66,7 & 3 & 20 \\
Naik & 2 & 13,3 & 3 & 20 \\
\hline Total & 15 & 100 & 15 & 100 \\
\hline \multicolumn{1}{c}{ Uji independent t test $p=0.013$} \\
\hline
\end{tabular}

\section{PEMBAHASAN}

1. Mengidentifikasi tekanan darah sebelum dan sesudah diberikan air kelapa muda pada kelompok perlakuan pada lansia di Posyandu Usila Puskesmas Perak Timur Surabaya

Hasil statistik uji paired t test (tabel 5) pada kelompok perlakuan menunjukkan $p=0.009$ maka diambil kesimpulan bahwa pada kelompok perlakuan ada pengaruh perubahan tekanan darah pre dan post setelah pemberian air kelapa muda. Data perubahan tekanan darah pada lansia yang menderita hipertensi pada kelompok perlakuan setelah dilakukan pemberian air kelapa muda terdapat penurunan tekanan darah sebanyak 10 lansia (66.7 \%), sedangkan 2 lansia (13.3 \%) mengalami peningkatan tekanan darah dan 3 lansia (20 \%) tidak ada perubahan tekanan darah atau tetap.

Hasil tabulasi silang (tabel 5) dari 15 lansia yang menderita hipertensi pada kelompok perlakuan yang tidak mengalami perubahan tekanan darah (tetap) adalah sebanyak 3 lansia (20 \%) yang mempunyai tingkat pendidikan rendah. Tingkat pendidikan secara tidak langsung juga mempengaruhi tekanan darah. tingkat pendidikan berpengaruh terhadap gaya hidup seperti kebiasaan merokok, minum alkohol, dan kebiasaan melakukan aktifitas fisik seperti olahraga. Hasil Riskesdas (2013) menyatakan bahwa penyakit hipertensi cenderung tinggi pada pendidikan rendah dan menurun sesuai dengan peningkatan pendidikan. tingginya risiko terkenan hipertensi pada pendidikan yang rendah, kemungkinan disebabkan karena kurangnya pengetahuan pada seseorang yang berpendidikan rendah terhadap kesehatan (Anggara dan Prayitno, 2013). Pengetahuan tentang penyakit hipertensi dan pengobatan serta pearawatnnya di rumah akan mempengaruhi kepatuhan dalam perawatan hipertensi. Rendahnya pengetahuan lansia tentang perawatan hipertensi menjadi salah satu hambatan 
untuk berhasilnya kepatuhan dalam perawatan hipertensi, karena penderita kurang mendapat penyuluhan dan informasi yang adekuat dari petugas kesehatan. Pengetahuan tentang hipertensi berkaitan erat dengan tingkat pendidikan lansia dan juga berkaitan dengan sering atau tidaknya lansia memperoleh pendidikan kesehatan tentang perawatan hipertensi (Suhadi, 2011).

Hasil tabulasi silang (tabel 5) dari 15 lansia yang menderita hipertensi pada kelompok perlakuan yang mengalami kenaikan tekanan darah adalah sebanyak 2 lansia (13,3 \%). Menurut Farapti \& Sayogo (2014) salah satu faktor risiko terjadinya hipertensi adalah rendahnya asupan kalium, yang salah satu penyebabnya adalah rendahnya asupan sayur dan buah yang umumnya tinggi kalium. Seperti pada penelitian Widyaningrum (2014) terdapat hubungan antara asupan natrium, kalium dan magnesium dengan tekanan darah pada lansia di kelurahan makamhaji. Konsumsi natrium yang berlebihan menyebabkan konsentrasi natrium di dalam cairan ekstraseluler meningkat yang dapat menyebabkan meningkatnya volume darah dalam tubuh, dengan demikian jantung harus memompa lebih giat sehingga tekanan darah menjadi naik (Muttaqin, 2009). Selain itu faktor lain yang dapat mempengaruhi hipertensi adalah stress karena lingkungan (Reny, 2016).

Air kelapa muda mempunyai kandungan yang terdiri dari $17 \%$ kalium, 15\% magnesium dan 10\% vitamin C. Kandungan yang dimiliki air kelapa muda dipercaya dapat menurunkan tekanan darah (Darmawan, 2013).
Kandungan mineral kalium yang dapat menjaga dinding pembuluh darah tetap elastis, mengurangi penyempitan pembuluh darah sehingga pembuluh darah menjadi lebar, mengurangi sekresi renin, menurunnya aldosteron dan mempunyai efek dalam pompa Na-K yaitu kalium dipompa dari cairan ekstraseluler ke dalam sel, dan natrium di pompa keluar. Sehingga kalium dapat menurunkan tekanan darah (Muttaqin, 2009).

Peneliti berasumsi bahwa penurunan tekanan darah yang signifikan pada kelompok perlakuan (tabel 5) sebanyak 10 responden (66.7 \%) disebabkan karena konsumsi air kelapa muda sebanyak $250 \mathrm{ml}$ dalam 2 minggu 2 kali sehari (pagi dan sore). Peneliti merekomendasikan air kelapa muda sebagai minuman herbal yang harus dikonsumsi secara rutin yang berfungsi sebagai alternatif pengobatan non-farmakologi untuk menurunkan tekanan darah tinggi.

\section{Mengidentifikasi tekanan darah sebelum dan sesudah diberikan air kelapa muda pada kelompok kontrol pada lansia di Posyandu Usila Puskesmas Perak Timur Surabaya.}

Hasil statistik uji paired $t$ test (tabel 6) pada kelompok kontrol menunjukkan $p=1.000$ maka diambil kesimpulan bahwa pada kelompok kontrol tidak ada perubahan tekanan darah pre dan post. Data perubahan tekanan darah lansia yang menderita hipertensi pada kelompok kontrol didapatkan sebanyak 3 lansia (20\%) mengalami penurunan tekanan darah, sedangkan 9 lansia $(60 \%)$ tidak mengalami kenaikan tekanan darah 
atau tetap, dan 3 lansia (20 \%) mengalami peningkatan tekanan darah.

Berdasarkan hasil tabulasi silang jenis kelamin (tabel 1) pada kelompok kontrol paling banyak adalah responden perempuan yaitu responden laki-laki sebanyak 6 lansia (40 \%) dan responden perempuan sebanyak 9 lansia $(60 \%)$. Jenis kelamin (pria berusia 35-50 tahun dan wanita pasca menopause berisiko tinggi untuk mengalami hipertensi) (Ardiansyah, 2012). Perempuan akan mengalami peningkatan resiko tekanan darah tinggi (hipertensi) setelah menopause yaitu usia diatas 45 tahun. Perempuan yang belum menopouse dilindungi oleh hormon estrogen yang berperan dalam meningkatkan kadar High Density Lipoprotein (HDL). Kadar kolesterol HDL rendah dan tingginya kolesterol LDL (Low Density Lipoprotein) mempengaruhi terjadinya proses aterosklerosis dan mengakibatkan tekanan darah tinggi (Anggraini et.al, 2009).

Berdasarkan hasil tabulasi silang usia (tabel 2) pada kelompok kontrol paling banyak adalah usia responden 60-74 tahun sebanyak 12 lansia (80 \%) dan usia 75-90 tahun sebanyak 3 lansia (20\%). Hipertensi akan meningkat seiring bertambahnya umur seseorang. Individu yang berumur diatas 60 tahun, 50-60\% mempunyai tekananan darah lebih besar. Hal itu merupakan pengaruh degenerasi yang terjadi pada orang yang bertambah usianya (Susilo, 2011). Menurut Reny (2016) Ciri perseorangan yang mempengaruhi timbulnya hipertensi adalah umur (jika umur bertambah maka tekanan darah meningkat).
Berdasarkan hasil tabulasi silang penghasilan perbulan (tabel 3) pada kelompok kontrol paling banyak adalah penghasilan per bulan < 1.000 .000 rupiah sebanyak 14 lansia $(93.3 \%), \quad 1.000 .000$ rupiah 3.000.000 rupiah sebanyak 1 lansia (6.7 \%). Menurut Susilo (2011), stress akan meningkatkan resistensi pembuluh darah perifer dan curah jantung sehingga akan menstimulasi aktifitas saraf simpatis. Adapun stress dapat berhubungan dengan pekerjaan, ekonomi, dan karakteristik personal. Stress merupakan respon tubuh yang sifatnya nonspesifik terhadap setiap tuntutan beban atasnya. Hidup sehat dan menggunakan pola pikir sehat merupakan salah satu cara untuk mengendalikan stress.

Berdasarkan hasil tabulasi silang riwayat penyakit terdahulu (tabel 4) pada kelompok kontrol paling banyak adalah tidak ada sebanyak 9 lansia $(60 \%)$, asam urat sebanyak 3 lansia $(20 \%)$, kolesterol sebanyak 3 lansia (20\%), dan. Kurang olahraga atau kurang gerak dapat memicu kolestrol tinggi dan juga adanya tekanan darah yang terus menguat sehingga memunculkan hipertensi. Kandungan lemak yang berlebihan di dalam darah dapat menyebabkan timbunan kolestrol pada dinding pembuluh darah. Hal ini membuat pembuluh darah menyempit dan akibatnya tekanan darah akan meningkat (Susilo, 2011).

Peneliti berasumsi bahwa tidak ada pengaruh perubahan tekanan darah pre dan post pada kelompok kontrol disebabkan karena pada kelompok kontrol tidak diberikan air kelapa muda. Selain itu, ada beberapa faktor 
yang dapat mempengaruhi keadaan tersebut (tidak ada penurunan tekanan darah lansia yang menderita hipertensi pada kelompok kontrol) yaitu jenis kelamin, usia, keluarga yang menderita hipertensi, kebiasaan merokok, kegiatan olahraga sehari-hari, riwayat penyakit terdahulu, penghasilan perbulan, lama hipertensi.

\section{Menganalisis Pengaruh air kelapa muda terhadap penurunan tekanan darah tinggi pada lansia di Posyandu Usila Puskesmas Perak Timur Surabaya.}

Hasil penelitian dari tabel 7 menggunakan uji independent $t$ test untuk menunjukan perbedaan tekanan darah posttest pada kedua kelompok menunjukkan hasil $p=0.013(0.013<$ 0.05) yang berarti bahwa ada perbedaan tekanan darah posttest antara kelompok perlakuan dan kelompok kontrol pada lansia di Posyandu Usila Puskesmas Perak Timur Surabaya.

$$
\text { Menurut Vita (2016) }
$$

Komponen kalium dalam air kelapa muda lebih tinggi dibanding natriumnya, dan sesuai dengan elektrolit yang ada dalam tubuh kita. Oleh karena itu, World Health Organization (WHO) merekomendasikan untuk mengkonsumsi minuman tinggi kalium, guna mengurangi risiko hipertensi dan stroke.

Menurut penelitian Rini syafriani (2014) tentang The Effect of Coconut Water (Cocos nucifera L.) and An Isotonic Drink on The Change of Heart Rate Frequency in The Rats Induced Hypertension. Tujuan dari penelitian ini adalah untuk mengevaluasi pengaruh air kelapa muda (Cocos nucifera L) dan minuman isotonik terhadap perubahan frekuensi denyut jantung pada tikus yang diinduksi hipertensi. Kelompok perlakuan diberikan air kelapa muda dan kelompok kontrol diberikan minuman isotonic. Induksi hipertensi dengan pemberian larutan $\mathrm{NaCl}$ konsentrasi tinggi selama 14 hari, Tekanan dengan tekanan sistolik lebih dari $140 \mathrm{mmHg}$ dan tekanan diastolik lebih besar dari $90 \mathrm{mmHg}$. kemudian diberikan perlakuan ke masing-masing kelompok selama 14 hari. Hasil penelitian ini menunjukkan bahwa air kelapa (C. Nucifera L) menurunkan frekuensi detak jantung lebih baik dari pada minuman isotonik.

Pada tabel 5, hasil uji statistik paired t test pada kelompok perlakuan menunjukkan hasil ada pengaruh perubahan tekanan darah pre dan post setelah pemberian air kelapa muda. Sedangkan pada tabel 6 , hasil uji statistik paired t test pada kelompok kontrol menunjukkan hasil tidak ada pengaruh perubahan tekanan darah pre dan post. Maka dapat disimpulkan pada kelompok perlakuan ada perubahan tekanan darah pada lansia yang menderita hipertensi terdapat penurunan yang signifikan dibandingkan dengan kelompok kontrol yang tidak terjadi penurunan tekanan darah secara signifikan.

Peneliti berasumsi bahwa perubahan tekanan darah yang signifikan pada kelompok perlakuan disebabkan oleh konsumsi air kelapa muda dapat menurunkan tekanan darah pada lansia yang menderita hipertensi, sehingga bagi para lansia yang menderita hipertensi sebaiknya mengkonsumsi air kelapa muda 
sebagai salah satu pengobatan alternatif non-farmakologi untuk menurunkan tekanan darah.

\section{KESIMPULAN}

Berdasarkan hasil temuan penelitian dan hasil pengujian pada pembahasan yang dilaksanakan, maka dapat diambil kesimpulan sebagai berikut:

1. Adanya penurunan rata-rata tekanan darah sistolik yang signifikan sebelum dan sesudah pemberian air kelapa muda pada kelompok perlakuan.

2. Adanya penurunan rata-rata tekanan darah sistolik yang minimal sebelum dan sesudah pengukuran tekanan darah pada kelompok kontrol.

3. Pemberian air kelapa muda secara teratur lebih efektif untuk menurunan tekanan darah tinggi pada lansia di Posyandu Usila Puskesmas Perak Timur Surabaya.

\section{DAFTAR PUSTAKA}

Anggara \& Prayitno. 2013. Faktorfaktor yang berhubungan dengan tekanan darah di puskesmas telaga murni, cikarang barat tahun 2012. program studi S1 kesehatan masyarakat stikes MH.Thamrin. Jakarta. jurnal ilmiah kesehatan. http://webcache.googleusercont ent.com/search?q=cache:NVhQ OHh9IlkJ:1p3m.thamrin.ac.id/up load/artikel\%25204.\%2520vol\% 25205\%2520no\%25201 feby.p $\mathrm{df}+\& \mathrm{~cd}=1 \& \mathrm{hl}=\mathrm{id} \& \mathrm{ct}=\mathrm{c} \ln \mathrm{k} \& \mathrm{gl}=$ id di unduh pada tanggal 09 Mei 2017 pukul 15.20 WIB.

Anggraini, AD., et al. 2009. FaktorFaktor Yang Berhubungan Dengan Kejadian Hipertensi
Pada Pasien Yang Berobat Di Poliklinik Dewasa Puskesmas Bangkinang. Skripsi. Fakultas Kesehatan Universitas Riau. https://yayanakhyar.files.wordpr ess.com/2009/02/files-ofdrsmed-faktor-yangberhubungan-dengan-kejadianhipertensi.pdf Diunduh pada tanggal 23 Mei 2017 Pukul $12.00 \mathrm{WIB}$

Ardiansyah, M. (2012). Medikal Bedah Untuk Mahasiswa. Jogjakarta: DIVA Press.

Arsa M. Kandungan natrium dan kalium larutan isotonik alami air kelapa muda. magister thesis. Denpasar : Universitas Udayana. 2011 . http://www.pps.unud.ac.id/thesi s/pdf thesis/unud-4261724220385cover $\% 20$ tesis $\% 20$ made $\% 20$ ars a.pdf di unduh pada tanggal 10 Mei 2017 pukul 09.00 WIB

Darmawan, B.D. (2013). Diit Sehat Air Kelapa untuk Kecantikan dan Penyembuhan macam-macam Penyakit. Yogyakarta: Media Pressindo

Dinkes Surabaya, 2015. Profil Kesehatan Tahun 2015, http://dinkes.surabaya.go.id/porta 1/profil/dkk-dalamangka/statistik-10-penyakitterbanyak/ diakses pada tanggal 01 Januari 2017 pukul 19.00 Wib.

Fahriza, et al. (2014). Pengaruh Terapi Herbal Air Kelapa Muda Terhadap Penurunan Tekanan Darah Pada Penderita Hipertensi Di Desa Tambahrejo Kecamatan Bandar Kabupaten Batang. 


\begin{abstract}
Fakultas Kedokteran Universitas Sultan Agung Semarang.http://182.253.197.10 0/ejournal/index.php/ilmukepera watan/article/view/241 diunduh pada tanggal 28 Desember 2016 pukul 10.00 WIB
\end{abstract}

Farapti \& Sayogo. (2014). Air Kelapa Muda-Pengaruhnya Terhadap Tekanan Darah. Continuing Professional Development. https://www.researchgate.net/pu blication/315096822_Air_Kelap a Muda Pengaruhnya terhadap Tekana n Darah diunduh pada tanggal 08 Januari 2017 pukul 13.20 WIB

Farapti et al,. 2013. effect of tender coconut water on systolic and diastolic blood pressure in prehypertensive women. Health Science Indones 2013. http://ejournal.litbang.depkes.go .id/index.php/HSJI/article/view/ $\underline{3433}$ diunduh pada tanggal 11 Mei 2017 pukul 10.25 WIB

Laode, S. (2012). Asuhan Keperawatan Gerontik. Yogyakarta: Nuha Medika

Muttaqin, A. (2009). Pengantar Asuhan Keperawatan Klien Dengan Gangguan Sistem Kardiovaskular. Jakarta: Salemba Medika

Nursalam. (2013). Metodologi Penelitian Ilmu Keperawatan. Jakarta: Salemba Medika.

Ong KL, Cheung BM, Mn YB, Lam KS. Prevalence, Awareness, Treatment and Control of Hypertension Among United States Adults 1999-2004. Hypertension 2007;49(1):69-75. http://hyper.ahajournals.org/con tent/49/1/69.short diunduh pada tanggal 11 Januari 2017 pukul $08.20 \mathrm{WIB}$

Prasetyaningrum. (2014). Hipertensi Bukan Untuk Ditakuti. Jakarta: F Media

Reny. (2014). Buku Ajar Asuhan Keperawatan Gerontik Jilid I. Jakarta: Trans Info Media - (2016). Buku Ajar Asuhan Keperawatan Klien Dengan Gangguan Kardiovaskular Aplikasi NIC \& NOC. Jakarta: EGC

Rini Syafriani et al,.(2014). The Effect of Coconut Water (Cocos nucifera L.) and An Isotonic Drink on The Change of Heart Rate Frequency in The Rats Induced Hypertension. International Seminar on Natural Product Medicines, ISNPM 2012. Elsevier. http://www.sciencedirect.com/s cience/article/pii/S18766196140 $\underline{02125}$ di unduh pada tanggal 05 januari 2017 pukul 14.30 WIB.

Riskesdas, (2013). Hasil Kesehatan Dasar 2013, http://www.depkes.go.id/resourc es/download/general/Hasil\%20Ri skesdas\%202013.pdf diakses pada tanggal 27 Desember 2016 pukul 14.30 Wib.

Suhadi.(2011). Analisis Faktor-Faktor Yang Mempengaruhi Kepatuhan Lansia Dalam Perawatan Hipertensi Di Wilayah Puskesmas Srondol Kota Semarang. Tesis http://lib.ui.ac.id/file?file=digital/ 20282617-T\%20Suhadi.pdf diunduh pada tanggal 29 Mei 2017 Pukul 06.00 WIB. 
Sulistyaningsih. (2011). Metodologi

Penelitian Kebidanan

Kuantitatif-Kualitatif.

Yogyakarta: Graha Ilmu.

Susilo, Y dan Wulandari, A. (2011).

Cara Jitu Mengatasi Hipertensi.

Yogyakarta: ANDI

Vita, D. (2016). Kelapa Muda.

Surabaya: Stomata

Widyaningrum, TA. 2014. Hubungan

Asupan Natrium, Kalium,

Magnesium dan Status Gizi

dengan Tekanan Darah pada

Lansia di Kelurahan Makamhaji

Kartasura. Skripsi. Program

Studi Ilmu Gizi Fakultas Ilmu

Kesehatan Universitas

Muhammadiyah Surakarta.

http://eprints.ums.ac.id/29084/9/

02. Naskah Publikasi.pdf

Diunduh pada tanggal $20 \mathrm{Mei}$

2017 pukul $18.30 \mathrm{WIB}$ 